\title{
Using hydrodynamic model to predict PFOS and PFOA transport in the Daling River and its tributary, a heavily polluted river into the Bohai Sea, China
}

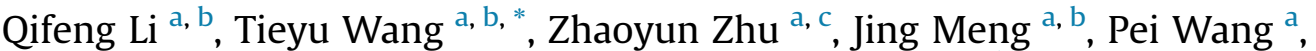 \\ Sarvajayakesavalu Suriyanarayanan ${ }^{\mathrm{d}, \mathrm{e}}$, Yueqing Zhang ${ }^{\mathrm{a}, \mathrm{b}}$, Yunqiao Zhou ${ }^{\mathrm{a}, \mathrm{b}}$, \\ Shuai Song a, Yonglong Lu ${ }^{a, b}$, Baninla Yvette ${ }^{a, b}$ \\ a State Key Lab of Urban and Regional Ecology, Research Center for Eco-Environmental Sciences, Chinese Academy of Sciences, Beijing 100085, China \\ ${ }^{\mathrm{b}}$ University of Chinese Academy of Sciences, Beijing 100049, China \\ ${ }^{c}$ Environmental Protection Bureau of Yinan County, Yinan 276300, China \\ d SCOPE (Scientific Committee on Problems of the Environment) Beijing Office, Beijing 100085, China \\ e Department of Water and Health, Faculty of Life Sciences, JSS University, Mysore 570015, India
}

\section{H I G H L I G H T S}

- PFOS and PFOA transportations were simulated by one dimensional hydrological model.

- Spatial distribution and mass flow of PFOS and PFOA were determined in the Daling River.

- Concentrations of PFOS and PFOA would not reach harmful level with the current load.

- The methodology used in present study might serve for other POP's assessment.

\section{A R T I C L E I N F O}

\section{Article history:}

Received 10 July 2016

Received in revised form

26 September 2016

Accepted 26 September 2016

Available online 12 October 2016

Handling Editor: Shane Snyder

\section{Keywords:}

PFOS

PFOA

DHI MIKE11 river model

Fluorine industrial parks

Risk assessment
G R A P H I C A L A B S T R A C T

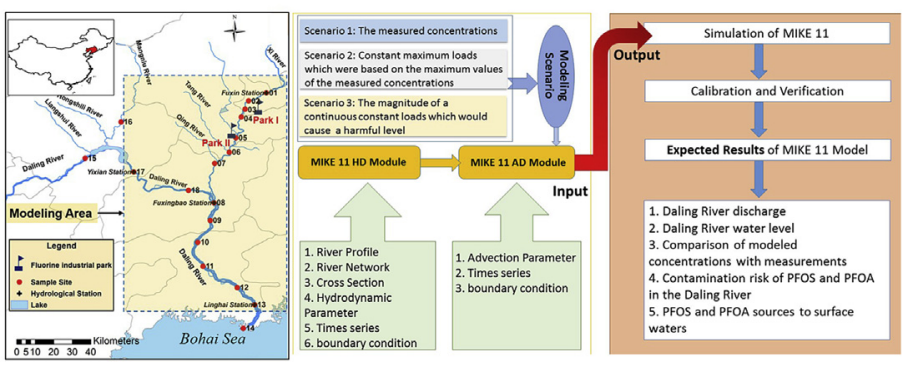

\begin{abstract}
A B S T R A C T
Perfluorooctane sulfonate (PFOS) and perfluorooctanoic acid (PFOA) are extremely persistent in the environment, and have the potential for long-range transport. The present study focused on the Daling River and its tributary, a larger river flowing into Liaodong Bay of the Bohai Sea. Recent studies have shown the elevated levels of PFOS and PFOA in the Daling River. Hence, the objective of this study was to investigate the seasonal changes, fate and transport modeling of PFOS and PFOA concentrations using one-dimensional DHI MIKE-11 river model. We designed three scenarios to assess the risk of PFOS and PFOA in surface water: the measured concentrations, constant maximum and the magnitude of a continuous constant load. The mean absolute errors divided by the mean of measured concentrations were $41-64 \%$ for PFOS and $29-36 \%$ for PFOA. The result indicated that PFOS and PFOA in the downstream of the Daling River would not reach a harmful level with the current load. The fluorochemical parks contributed an average of $44.57 \%$ of the total PFOS and $95.44 \%$ of the total PFOA flow that reached the estuary. The mass flow was observed as $1.74 \mathrm{~kg} \mathrm{y}^{-1}$ for PFOS and $40.57 \mathrm{~kg} \mathrm{y}^{-1}$ for PFOA to the Bohai Sea. These modeling results may be useful for monitoring the status and trends of emerging POPs and
\end{abstract}

\footnotetext{
* Corresponding author. State Key Lab of Urban and Regional Ecology, Research Center for Eco-Environmental Sciences, Chinese Academy of Sciences, Beijing 100085, China.
}

E-mail address: wangty@rcees.ac.cn (T. Wang). 
will help the determination of the risk to both humans and wildlife, in the estuarine and coastal areas of the Bohai Sea, China.

๑) 2016 Elsevier Ltd. All rights reserved.

\section{Introduction}

As a class of emerging persistent organic pollutants (POPs), perfluoroalkyl acids (PFAAs) have been widely used in manufacturing processes and products, such as polymers, surfactants, lubricants, pesticides, textile coatings, nonstick coatings, stain repellent, food packaging, and firefighting foams for more than 60 years (Giesy and Kannan, 2001; Giesy and Kurunthachalam, 2002; Wang et al., 2014; Liu et al., 2016). However, their persistence, hazardous effects, long-range transport and potential accumulation in food web attracted significant attention, especially perfluorooctane sulfonate (PFOS) and perfluorooctnoic acid (PFOA) (Thanh et al., 2009; Liu et al., 2015; Wang et al., 2015b; Sun et al., 2016). Due to the relatively high polarity and solubility of ionic PFAAs, water has become the primary reservoir of PFAAs and acts as the major medium for their transport (Prevedouros et al., 2006; Sharma et al., 2015; Wang et al., 2016). PFAAs can be biomagnified and passed to human (Wang et al., 2014). Although the production of PFOS and PFOA were restricted by the Stockholm convention, the production in China increased in recent years due to the usage exemption of specific products and huge demands for PFAAs containing products (Fu et al., 2015). Due to the bioaccumulation and extremely persistent nature of PFAAs there are still long-term public concern issues of adverse effects on ecosystem and human health as well as secondary release of PFAAs from environment (Wang et al., 2014, 2015b).

In order to meet the growing demand for surfactants and other surface modification applications, China has become one of the largest countries of PFOS and related chemicals production and consumption. From 2001 to 2006, the annual production of PFOS and related chemicals increased from less than $50 \mathrm{t}$ to about $250 \mathrm{t}$, and maintained a consistent until 2011. The cumulative historical production volume of PFOS and related chemicals were estimated to be 1800 t by 2011 (Xie et al., 2013). China also became the current world's largest PFOA/PFO emitter, with cumulative environmental releases reaching $250 \mathrm{t}$ in 2013 (Li et al., 2015). Hence, the most frequently detected PFAAs in the environment are PFOS and PFOA, and they may pose potential health risks on humans (Jiang et al., 2015). Wang et al. (2015a) reviewed PFOS and PFOA concentrations in water from the major river systems in China. It revealed that PFOS and PFOA in China are in the middle moderate levels compared with those in other countries or regions such as the USA, Canada, Japan and Europe.

Nonetheless, there is limited information regarding the characteristics of seasonal pollution together with transport behavior of PFOS and PFOA in water bodies in China. In order to manage the PFAAs in aquatic environment and control the emission of pollutants, it is essential to identify the seasonal changes, fate and transport modeling of PFOS and PFOA. To understand the fate, transport and risk of PFOS and PFOA in the Daling River and its tributaries, it is necessary to examine PFOS and PFOA concentrations in surface water in different seasons and model the daily discharge.

Simulation models are important tools to investigate various aspects of aquatic system for water management and decisionmaking. These quality models can be used to simulate surface and groundwater pollution, land use effects and wastewater treatment systems. The modules used in water quality models can be complex when simulating the cycle of pollutant buildup, washoff and impact (Eisakhani et al., 2012). These models not only represent the natural process but also hydraulic infrastructures, flow control structure and management rules (Doulgeris et al., 2012). The MIKE 11 is a powerful and popular hydrological modeling system, developed by the Danish Hydraulic Institute (DHI), which has been applied in simulating the fate and transport of HCB (Moshenberg, 2013), DDTs, PCBs and other POPs (Kaiglová et al., 2015).

In present study, the transport of PFOS and PFOA was modeled using DHI MIKE 11 river model to assess their transport from the fluorochemical park in the main tributaries of the Daling River to the downstream sites in the main stream where the industrial water enters the Bohai Sea.

\section{Materials and methods}

\subsection{Study area}

Daling River, one of the largest rivers in the west Bohai Bay, has a length of $397 \mathrm{~km}$ with a drainage area of 23, $263 \mathrm{~km}^{2}$. Xi River, which converges into the Daling River downstream, is the largest tributary flowing through Fuxin City. There are four hydrological stations along the modeling area: Yixian, Linghai, Fuxin, Fuxingbao stations. The first two stations located along the Daling River, and the last two along the Xi River. Water flows into the modeling area through the two upstream boundaries in the Daling River. The distance to the Linghai Station is $103 \mathrm{~km}$ from the Daling River boundary and $151 \mathrm{~km}$ from the Xi River boundary. The yearly average flows for the Xi River and Daling River are $3.52 \mathrm{~m}^{3} \mathrm{~s}^{-1}$ and $12.7 \mathrm{~m}^{3} \mathrm{~s}^{-1}$, respectively (Table $\mathrm{S} 1$ ). Daily water levels and discharge were obtained from Annual hydrological report (2013). The upstream boundary condition was set to measure water level at Yixian Station and Fuxin Station. The downstream boundary condition was set to measure water level at the Linghai station. Time series of water discharge and water level were used for the model input.

Fuxin City, a major concern for fluorochemical industries that is located on the proximity of the Xi River. In recent years, Fuxin City has been taking steps to develop the fluorochemical industry by establishing some fluorine chemical parks due to the abundance of mineral fluorite occurring $\left(\mathrm{CaF}_{2}\right)$ locally, and it has become the main fluorochemical industrial center in North China (Wang et al., 2013). Major fluorinated chemicals produced in these two fluorine chemical industrial parks were polytetrafluoroethylene (PTFE), fluorocarbon alcohol, hydrofluoroether, fluorinated intermediates, tetrafluoro coatings and other organic/inorganic fluorine products. The fluorochemical park I produced fluorinated chemicals $2911 \mathrm{t}$, 4014 t, $2911 \mathrm{t}$ and $2006 \mathrm{t}$ while park II produced $1000 \mathrm{t}, 1200 \mathrm{t}$, $1000 \mathrm{t}$ and $600 \mathrm{t}$ in spring, summer, autumn and winter of 2013, respectively (Fig. 1b). These two fluorine chemical parks were dominant point sources of PFAAs into the river. The fluorochemical park I had a wastewater capacity of $52,630 \mathrm{t} \mathrm{d}^{-1}, 71,884 \mathrm{t} \mathrm{d}^{-1}$, $82,523 \mathrm{t} \mathrm{d}^{-1}$ and 69,081 t d $\mathrm{d}^{-1}$ in spring, summer, autumn and winter of 2013 , respectively. On the other hand, or/similarly fluorochemical park II had $11,077 \mathrm{t} \mathrm{d}^{-1}, 12,371 \mathrm{t} \mathrm{d}^{-1}, 6633 \mathrm{t} \mathrm{d}^{-1}$ and 

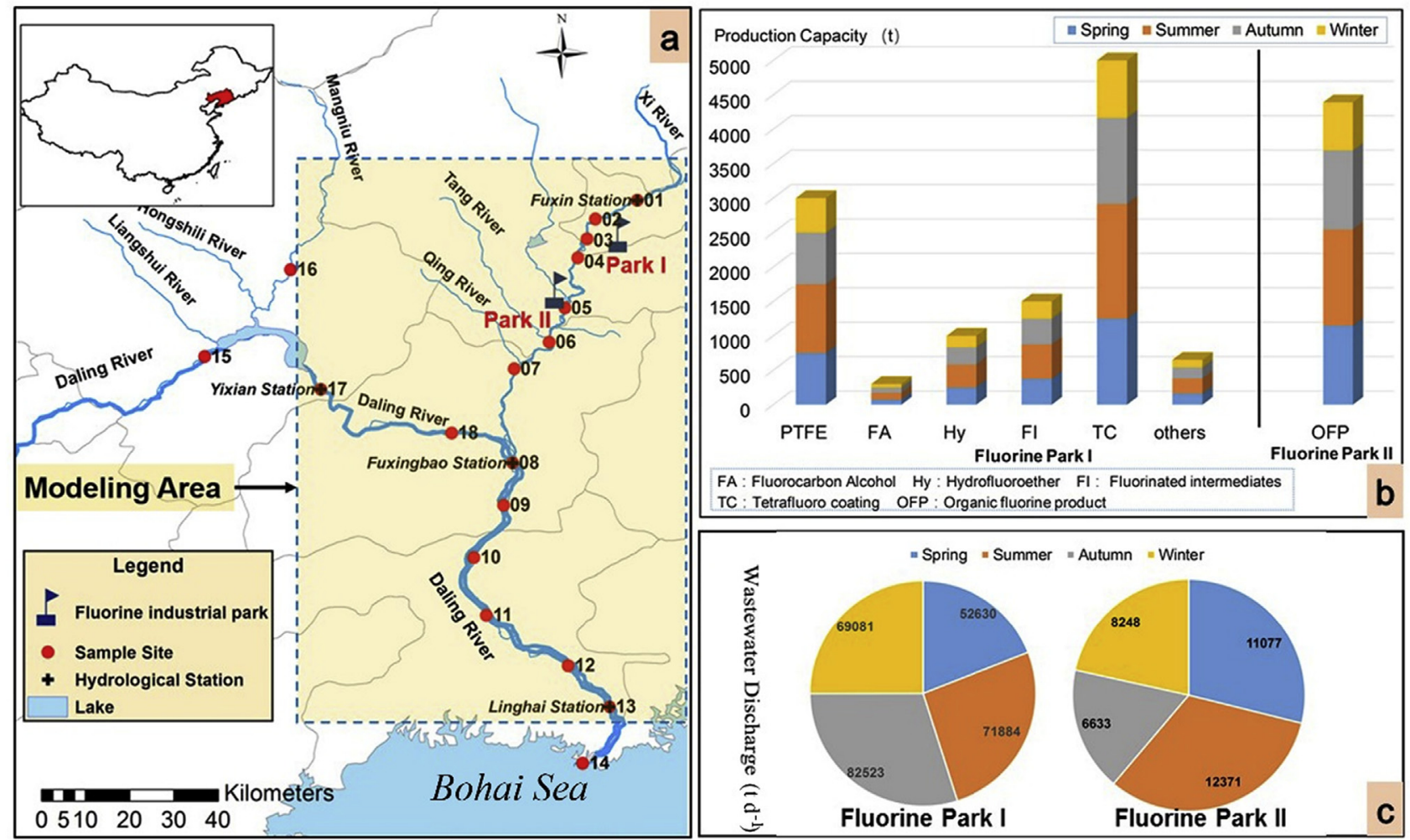

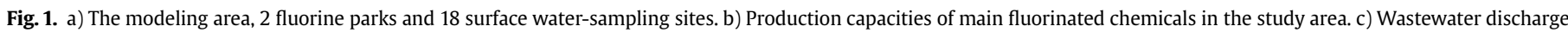
in the fluorine industrial parks.

$8248 \mathrm{t} \mathrm{d}^{-1}$ in spring, summer, autumn and winter of 2013, respectively (Fig. 1c) (FEPA, 2015). Wastewater samples were respectively collected at Site 03 near the fluorochemical park I and at Site 05 around the fluorochemical park II (Fig. 1a). The wastewater flowing from these plants was considered as contaminant source for modeling.

\subsection{MIKE 11 model}

One-dimensional numerical models are developed to stimulate the pollutant transport in rivers. MIKE-11 model is a popular European one-dimensional modeling system, used in water resource management, developed by the Danish Hydraulic Institute to simulate the pollutant transport, water flow in rivers and open channels. It is composed by several modules namely rainfall-runoff (RR), hydrodynamic (HD), advection-dispersion (AD) etc., which in some cases can be used in combination and in other cases as standalone simulators (DHI, 2009; Doulgeris et al., 2012).

MIKE-11 has 8 modules, which can be combined for different modeling purposes related to water engineering, water resources, water quality management and planning applications. It has a welldeveloped graphical user interface that support system interaction with the GIS (Johannessen et al., 2011). This investigation was conducted using hydrodynamic (HD), advection-dispersion (AD) modules to simulate the transport of PFOS and PFOA in the Daling River Catchment (Fig. 2).

HD module forming the core of the model, combining with AD module, was added to solve for water quality parameters. The HD module uses an implicit, finite difference scheme for the computation of unsteady flows in rivers. Both sub-critical and supercritical flow conditions were set up through a numerical scheme adapting to the local flow.
The equations formulated as follows (DHI, 2009): Continuity:

$\frac{\partial Q}{\partial x}+\frac{\partial A}{\partial t}=q$

Momentum:

$\frac{\partial Q}{\partial t}+\frac{\partial\left(\alpha \frac{Q^{2}}{A}\right)}{\partial x}+g A \frac{\partial h}{\partial x}+\frac{g Q|Q|}{C^{2} A R}=0$

Where $\mathrm{Q}$ is the discharge $\left(\mathrm{m}^{3} \mathrm{~s}^{-1}\right)$; $\mathrm{A}$ is the flow area $\left(\mathrm{m}^{2}\right)$; $\mathrm{q}$ is the lateral inflow $\left(\mathrm{m}^{2} \mathrm{~s}^{-1}\right)$; $\mathrm{h}$ is the stage above datum $(\mathrm{m}), \mathrm{C}$ is the Chezy resistance coefficient $\left(\mathrm{m}^{0.5} \mathrm{~s}^{-1}\right), \mathrm{R}$ is the hydraulic or resistance radius $(\mathrm{m}) ; \alpha$ is momentum distribution coefficient.

The AD module is based on the one-dimensional equation of conservation of mass of a dissolved or suspended material, i.e. the advection-dispersion equation. The module requires output from the hydrodynamic module, in time and space, in terms of discharge and water level, cross-sectional area and hydraulic radius.

The equation formulated as follows (DHI, 2009):

$\frac{\partial A C}{\partial t}=\frac{\partial}{\partial x}\left[A D \frac{\partial C}{\partial x}\right]-v \frac{\partial Q C}{\partial x}-A \cdot K \cdot C+C_{2} \cdot q$

Where $C$ is the concentration of the substance $\left(\mathrm{mg} \mathrm{L}^{-1}\right)$; $\mathrm{D}$ is the dispersion coefficient $\left(\mathrm{m}^{2} \mathrm{~s}^{-1}\right)$; A is the cross-section area $\left(\mathrm{m}^{2}\right)$; $\mathrm{k}$ is the linear decay coefficient $\left(\mathrm{s}^{-1}\right) ; \mathrm{C}_{2}$ is the source concentration $\left(\mathrm{mg} \mathrm{L}^{-1}\right) ; \mathrm{q}$ is the lateral inflow $\left(\mathrm{m}^{2} \mathrm{~s}^{-1}\right) ; \mathrm{x}$ is the space coordinate $(\mathrm{m})$; $\mathrm{t}$ is the time coordinate $(\mathrm{s})$. 


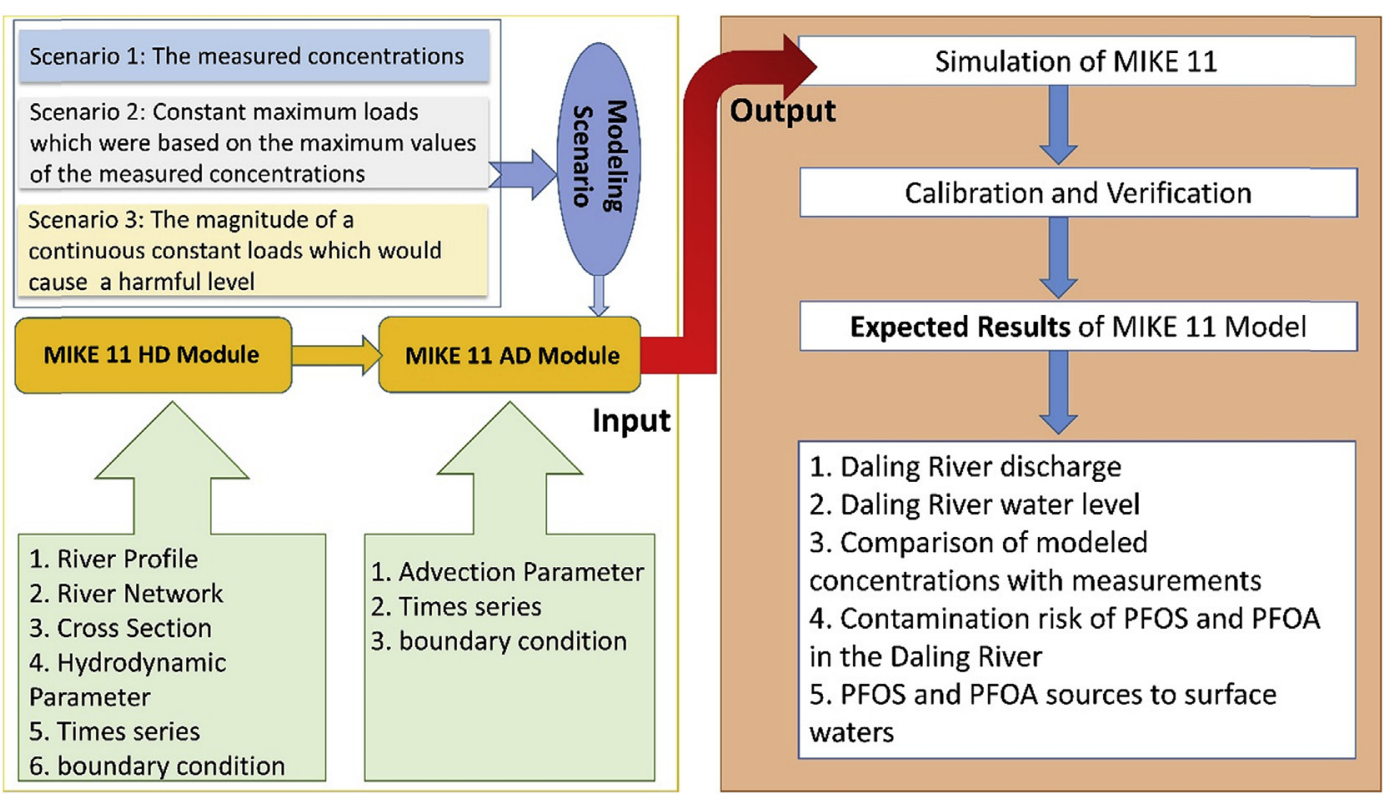

Fig. 2. Scenario setting and simulation of PFOS and PFOA using MIKE model.

\subsection{Data collection and MIKE 11 HD calibration}

PFOS and PFOA data were available in the published source (Zhu et al., 2015). The basic river network of the Daling River was search from the google earth. The cross section data was measured for every $5 \mathrm{~km}$ during the sampling period. The discharge and water level data was collected from the Annual hydrological report (2013).

We built the model parameters (Fig. 2) on the MIKE 11. The HD model components consist of the river network (Fig. S1), cross section (Fig. S2), discharge and water level time series (Fig. S3) and HD boundary condition (Fig. S4). For AD model, it consists of the PFOS and PFOA time series scenario (Table S2, Fig. 1) and AD boundary condition (Fig. S5).

The HD model calibration was analyzed by the water volume balance (Table S3) and some statistics method (Table S4). The relative deficit is 0 indicating that the volume balance does well in the model and is fitted to use in the AD model. The statistic results show that the discharge and water level simulated well in the model and is similar to the actual phenomenon of the Daling River.

\subsection{Modeling scenarios and assumptions}

In order to assess the modeling result, the simulated concentrations were compared with the measured surface water concentrations. Then in order to assess the PFOS and PFOA contamination risk of surface water, three scenarios were simulated (Fig. 2). In scenario 1, the model was run with an input of loads that change in time according to the concentration series interpolated from the measured concentrations. In scenario 2 , the model was run using constant maximum loads that were based on the maximum values of the measured concentrations in order to find out the maximum concentrations of the current PFOS and PFOA loads can cause. In scenario 3 , we estimated the magnitude of continuous constant PFOS and PFOA loads, which would cause the PFOS and PFOA concentrations at the estuary to raise a harmful level. For a threshold level of PFOS and PFOA concentration in the river water we chose the potential danger to human health of PFOS and PFOA values of $1 \mu \mathrm{g} \mathrm{L}^{-1}$ and $5 \mu \mathrm{g} \mathrm{L}^{-1}$ for water quality in drinking water (Inspectorate, 2009).

As PFOS and PFOA practically do not degrade in the environment or absorbed to the sediment, they were modeled as a conservative substance unaffected by the process. Therefore, the decay rates were set to be small $\left(10^{-7} \mathrm{~d}\right)$ that they behaved as conservative tracers. PFOS and PFOA loads were fed into the model as concentrations.

\section{Results and discussions}

\subsection{Spatial distribution of PFOS and PFOA in surface water}

Quantifiable concentrations of PFOS were found in all sampling points and variations in different season were observed. The mean concentration of PFOS during spring ranged from $0.59 \mathrm{ng} \mathrm{L}^{-1}$ to $482.99 \mathrm{ng} \mathrm{L}^{-1}$ (averaged $56.77 \mathrm{ng} \mathrm{L}^{-1}$ ). In summer, it stood at $1.02 \mathrm{ng} \mathrm{L}^{-1}$ to $21.21 \mathrm{ng} \mathrm{L}^{-1}$ (averaged $3.99 \mathrm{ng} \mathrm{L}^{-1}$ ). Meanwhile in autumn it was $0.16 \mathrm{ng} \mathrm{L}^{-1}$ to $2.27 \mathrm{ng} \mathrm{L}^{-1}$ (averaged $0.87 \mathrm{ng} \mathrm{L}^{-1}$ ) and in winter $0.87 \mathrm{ng} \mathrm{L}^{-1}$ to $39.86 \mathrm{ng} \mathrm{L}^{-1}$ (averaged $8.15 \mathrm{ng} \mathrm{L}^{-1}$ ). A relatively clear seasonal trend that was observed showed that the average concentration of PFOS in spring was the highest, followed by winter, summer and autumn. The average concentration of PFOS in spring indicated seven times higher compared with winter; fourteen times higher compared with summer and sixty times higher than autumn. The seasonal variations were assessed by the method of One-Way Analysis of Variance (ANOVA) in Origin 9.1. The overall ANOVA value is $0.016(P<0.05)$ meaning that it has a significant difference of at least two seasons. According to the Fisher Test results, the PFOS concentration in spring was of significant difference with other seasons in the Daling River. The increasing concentration generally caused by decrease of water level and flow during the spring season. Fig. S6(a) shows the distribution of PFOS in seasonal water from the study area. The PFOS concentration in the Xi River was higher than in the Daling River in most sampling sites. Site 01 located in the Fuxin County, showed a higher PFOS. This probably came from daily life sources. Site 05 near the fluorine chemical park II, PFOS was the highest in spring because the park perhaps caused more emission during the season.

The levels of PFOA varied in different seasons than the 
concentrations of PFOA in water samples. In spring, it ranged from $0.47 \mathrm{ng} \mathrm{L}^{-1}$ to $749.30 \mathrm{ng} \mathrm{L}^{-1}$ (averaged $158.0 \mathrm{ng} \mathrm{L}^{-1}$ ) summer, $2.51 \mathrm{ng} \mathrm{L}^{-1}$ to $2279 \mathrm{ng} \mathrm{L}^{-1}$ (averaged $522.71 \mathrm{ng} \mathrm{L}^{-1}$ ), autumn and winter showed a low detection of $675.39 \mathrm{ng} \mathrm{L}^{-1}$ (averaged $210.86 \mathrm{ng} \mathrm{L}^{-1}$ ) and from $0.27 \mathrm{ng} \mathrm{L}^{-1}$ to $752.76 \mathrm{ng} \mathrm{L}^{-1}$ (averaged $212.67 \mathrm{ng} \mathrm{L}^{-1}$ ), respectively. The average concentration of PFOA in summer was the highest, followed by winter, autumn and spring. Subsequently, PFOA in summer doubled compared with that in winter and autumn and three times higher than spring. The seasonal variations were also assessed by the method of One-Way Analysis of Variance (ANOVA) in Origin 9.1. The overall ANOVA value is $0.038(P<0.05)$ meaning that it is significantly different at least for two seasons. According to the Fisher Test results, the concentration in summer was significantly different with other seasons in the Daling River because of the highest production of fluorinated chemicals (Fig. 1b). Fig. S6 (b) shows the distribution of PFOA in seasonal water from the study area. The PFOA concentration in the Xi River was higher than that in the Daling River. Site 03 and 05 located near the fluorine chemical park, PFOA was the highest belonging to the industrial emissions. In the confluence of the two rivers, the PFOA descended into Daling River, a fresh river upstream and then kept a relativity level and flowed into the Liaodong Bay in the north Bohai, in China.

The strong seasonal variations are related to two factors. The first one was the production capacities in the fluorine chemical parks were different during different seasons. The highest total production capacity of fluorinated chemicals was in summer (6214 t), followed by spring (3911 t) and autumn (3911 t), while the lowest capacity was noticed in winter (2606 t). The second reason was that water from the upstream varied with seasons accordingly. Water flow in the upstream of the fluorochemical parks was $0.01 \mathrm{~m}^{3} \mathrm{~s}^{-1}, 2.06 \mathrm{~m}^{3} \mathrm{~s}^{-1}, 1.09 \mathrm{~m}^{3} \mathrm{~s}^{-1}$ and $0.31 \mathrm{~m}^{3} \mathrm{~s}^{-1}$ during spring, summer, autumn and winter, respectively (Annual hydrological report, 2013). The increasing concentration of PFOS in spring was generally caused by the lower water flow. But for PFOA, the concentration in summer was significantly higher than those in other three seasons, because of the highest production of fluorinated chemicals. Therefore, the concentrations of PFOS and PFOA varied in seasons. As a result, the major emission of PFOS in the fluorine chemical park was in spring while the PFOA was in summer.

Notwithstanding, the emission of PFOA was higher than PFOS in both areas of the fluorine chemical park. The possible reasons were that production intensity and structure were different in seasons and the PFOS usage was controlled by the local government following the Convention of Stockholm.

The present findings of PFOS and PFOA concentrations in surface water samples were compared with the available worldwide data. The comparative study suggests that the PFAAs pollution of the study area is moderate in a global level. Concentrations of PFAAs were either comparable to or higher than those detected in coastal waters of Yodo River Basin, in Japan (Lein et al., 2008), South Korea (Rostkowski et al., 2006; Naile et al., 2010), and various river and coastal waters in Brazil (Quinete et al., 2009). Concentrations of PFOS and PFOA measured in this study were comparable to those reported for Tokyo Bay, Japan (Sakurai et al., 2010; Yamashita et al., 2005). In the present study, the maximum concentration of PFOS (482.99 $\mathrm{ng} \mathrm{L}^{-1}$ ) is higher than the greatest concentrations of PFOS (123 $\mathrm{ng} \mathrm{L}^{-1}$ ) in the Yodo River Basin, Japan. The measured concentration of PFOA $\left(2.28 \mu \mathrm{g} \mathrm{L}^{-1}\right)$ in the Daling River, is lower than the greatest concentration of PFOA $\left(2.6 \mu \mathrm{g} \mathrm{L}^{-1}\right)$ measured in the Yodo River Basin, which is one of the most polluted rivers in Japan (Wang et al., 2015a,b).

The possible source for the observed increase were from the flourochemcial manufacturing facility located in the study area especially the 3rd and 5th sampling sites. The concentrations were found lower than the level of available level criteria of USEPA (USEPA, 2009). The concentrations observed in the study area near the Liaodong Bay are similar to the concentrations in the Bohai Sea observed by Zhao et al. (2007) and Gao et al. (2014). Therefore, the Daling River and its tributary seems to act as major sources of PFOS and PFOA in Bohai Sea Region where they are transported via the Liaodong Bay into the Bohai Sea.

\subsection{Comparison of modeled concentrations with measurements}

The measured and modeled PFOS and PFOA surface water concentrations at sampling sites are presented in Fig. 3. The measured and modeled concentrations were the same at Site 01 near the $\mathrm{Xi}$ River boundary, Site 13 near the downstream boundary and Site 17 near the upstream boundary of the Daling River, where the input concentrations were set equal to the measured value. The Sites 0113 are in order from the upstream of the Xi River to the confluence with the Daling River and then downstream of the watershed. Fig. 3 shows that spatial concentration trends of PFOS and PFOA can be reasonably predicted by the MIKE 11 model. For PFOS (Fig. 3), the mean absolute error divided by the mean of measured concentrations was $41-64 \%$ in different seasons. For PFOA (Fig. 4), the error was $29-36 \%$ in different seasons. Linear regression of the PFOS are weaker $\left(R^{2}=0.03-0.16\right)$ than PFOA $\left(R^{2}=0.65-0.85\right)$ with the best correlation with the MIKE 11 model. The modeled concentrations are alternately higher and lower than the measured concentrations, suggesting that the model error is not systematic.

The observed differences between the measured and simulated concentrations seen in Fig. 3 are not only due to uncertainties in the model: As the surface water samples were taken as grab samples, the concentrations fluctuated greatly in different sites, while the modeled concentrations were highly dependent on the concentrations of incoming water. As Happonen et al. (2016) studied in south-western Finland, it is likely that the uncertainty originating from sampling is greater than the uncertainty in the model on one hand. On the other hand, the possible source of model uncertainty is an error in the water flows, but as the flow was forced to match the measured flows of the hydropower plants through the model, the flow error should be relatively small.

Our model performance results are in line with other PFAAs modeling studies: Earnshaw et al. (2014) reported about 2.0 or 2.5 times higher modeled PFOA concentrations compared to measured concentrations based on different parameters. The ratios of modeled PFOS concentrations to observed concentrations of Miyake et al. (2014) were $0.79-1.8$ for surface seawater, $0.73-1.4$ for intermediate seawater and $0.59-1.3$ for bottom seawater. In this study the ratios ranged from 0.7 to 2.7 for PFOS, when excluding the measured results in Site 02-04 in April, and from 0.66 to 1.88 for PFOA. The ratios ranged from 0.1 to 2.3 for PFOA in the study of Happonen et al. (2016). The measured PFOS concentrations were considerably higher than the PFOA concentrations in our study: from <LOQ $0.3 \mathrm{ng} \mathrm{L}^{-1}$ to $20.7 \mathrm{ng} \mathrm{L}^{-1}$ (Earnshaw et al., 2014) and 1.5-7.3 $\mathrm{ng} \mathrm{L}^{-1}$ (Miyake et al., 2014). The agreement between the measured and simulated PFOS and PFOA loads are acceptable, especially at the higher concentration level. Therefore, the uncertainty from the sample analysis was likely to be lower in these studies.

\subsection{Contamination risk of $P F O S$ and $P F O A$}

In order to find out the probable range of PFOS and PFOA concentrations in the Daling River under the current PFOS and PFOA emission, the transport of PFOS and PFOA was simulated using scenario 1 with load input based on the measured concentrations. In scenario 2, constant maximum load was determined from the 


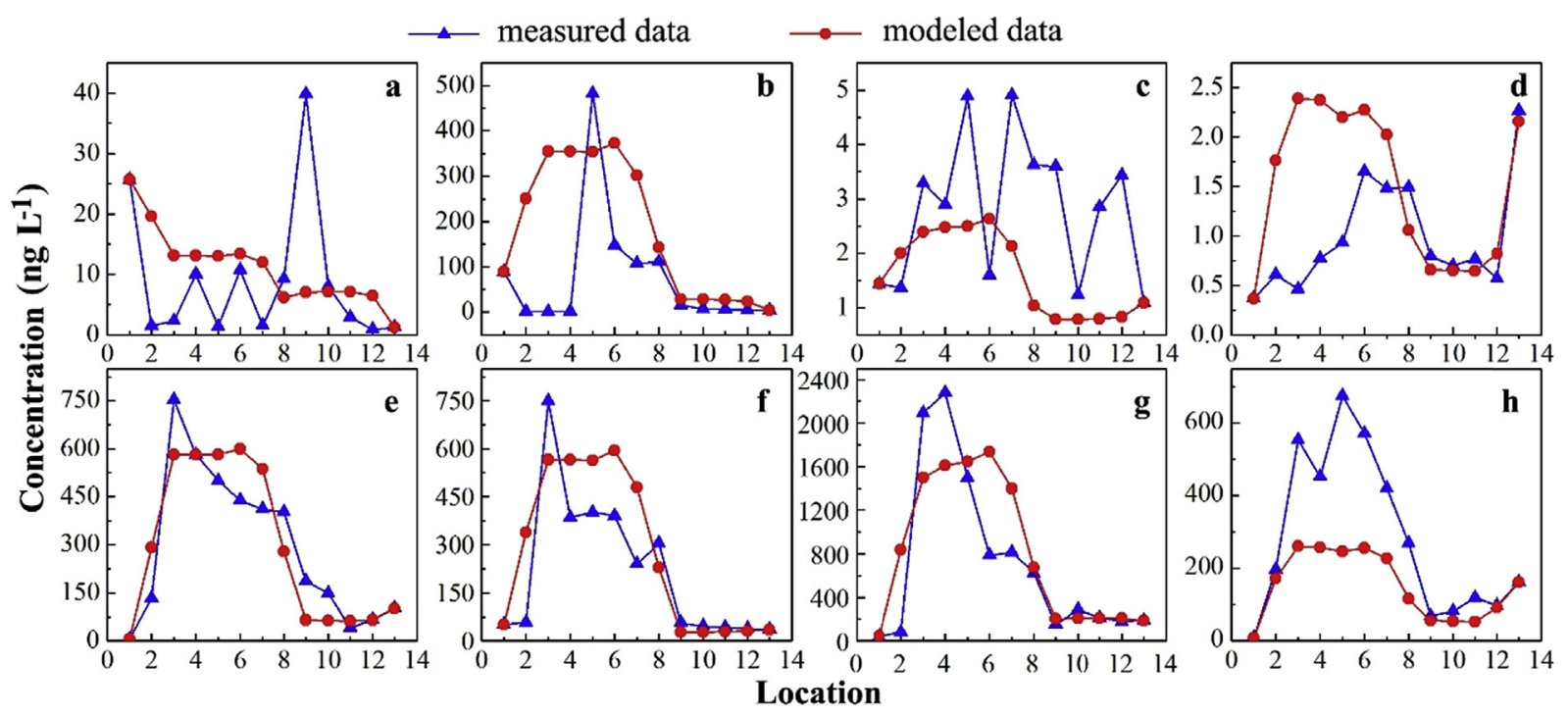

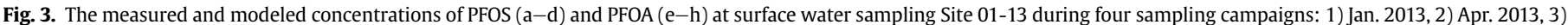
Jul. 2013, 4) Oct. 2013.

maximum values of the measured concentrations (Fig. 4). The PFOS concentrations at the section near the downstream of Linghai Station was observed as $0.05-63.75 \mathrm{ng} \mathrm{L}^{-1}$ in scenario 1 and 0.5-150.22 $\mathrm{ng} \mathrm{L}^{-1}$ in scenario 2 , where PFOA concentrations were observed as $1.06-288.86 \mathrm{ng} \mathrm{L}^{-1}$ in scenario 1 and 3.39-730.63 $\mathrm{ng} \mathrm{L}^{-1}$ in scenario 2. The modeled maximum PFOS concentrations in scenario 1 was $63.75 \mathrm{ng} \mathrm{L}^{-1}$ and in scenario 2 was $150.22 \mathrm{ng} \mathrm{L}^{-1}$. It represents $31.86 \%$ and $75.11 \%$ respectively, of the USEPA guideline value $200 \mathrm{ng} \mathrm{L}^{-1}$ for provisional health advisory (USEPA, 2009). The modeled maximum PFOA concentrations was $288.86 \mathrm{ng} \mathrm{L}^{-1}$ in scenario 1 while $730.63 \mathrm{ng} \mathrm{L}^{-1}$ in scenario 2 . It represents $72.21 \%$ and $182.66 \%$ respectively, of the USEPA guideline value $400 \mathrm{ng} \mathrm{L}^{-1}$ for provisional health advisory (USEPA, 2009). The results reveal that PFOS and PFOA in the Daling River at the downstream would not reach a harmful level with the current PFOS and PFOA load. However, the current PFOS and PFOA concentration in the Daling River is likely to be a considerably important source of PFOS and PFOA to the environment, the coastal ecosystem and human beings near the river.

In scenario 3, the magnitude of a continuous constant PFOS and PFOA load that would increase the PFOS and PFOA concentration in the estuary that exceeds from the guideline value (Inspectorate, 2009) of $1 \mu \mathrm{g} \mathrm{L}^{-1}$ and $5 \mu \mathrm{g} \mathrm{L}-1$ (Fig. 5).

By trial and error, the critical loads were found to be approximately $36.60 \mathrm{~kg} \mathrm{y}^{-1}$ for PFOS and $185.78 \mathrm{~kg} \mathrm{y}^{-1}$ for PFOA. The size of the critical load depends on both the flow situation and the distance of the fluorochemical park from the estuary. At the assumed continuous load level of $36.60 \mathrm{~kg} \mathrm{y}^{-1}$ for PFOS and $185.78 \mathrm{~kg} \mathrm{y}^{-1}$ for PFOA, the threshold of $1 \mu \mathrm{g} \mathrm{L}{ }^{-1}$ for PFOS and $5 \mu \mathrm{g} \mathrm{L}^{-1}$ for PFOA was exceeded during winter and spring in 2013. Fig. 6 represents the effect of the $36.60 \mathrm{~kg} \mathrm{y}^{-1}$ load on PFOS concentration and $185.78 \mathrm{~kg} \mathrm{y}^{-1}$ load on PFOA concentration at the Linghai Station

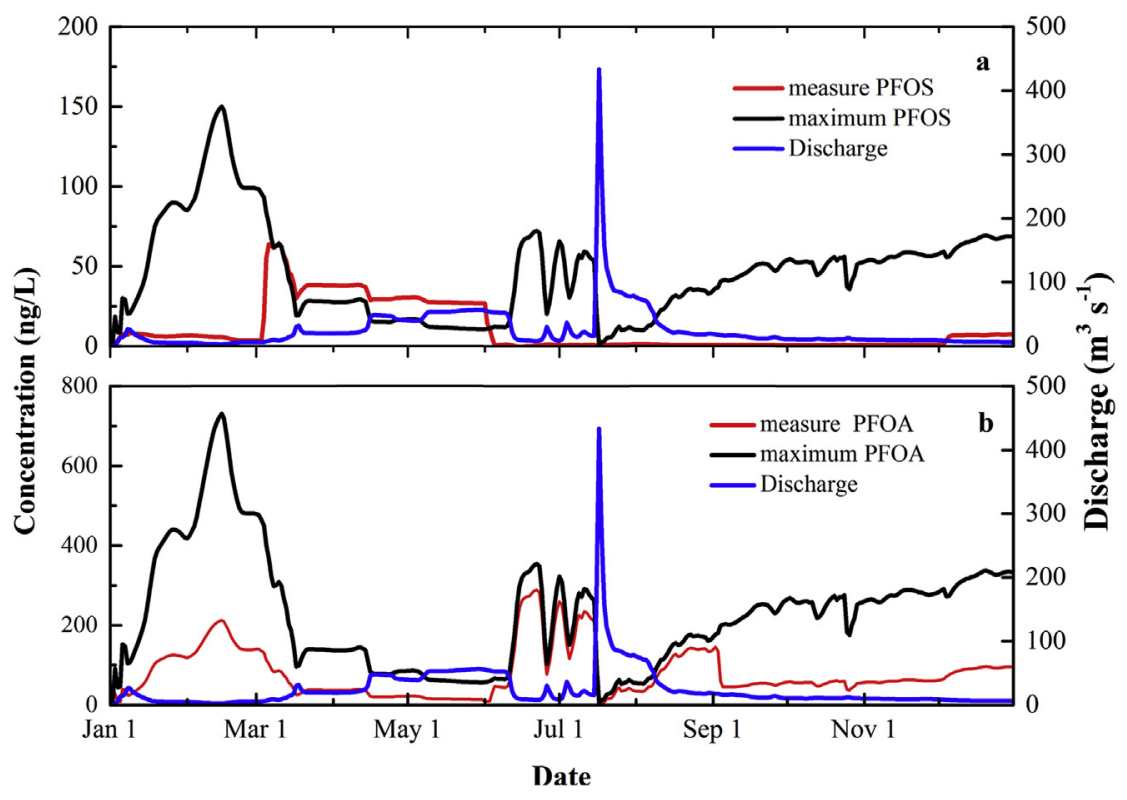

Fig. 4. The modeled PFOS (a) and PFOA (b) concentrations at the section near the Linghai Station. 


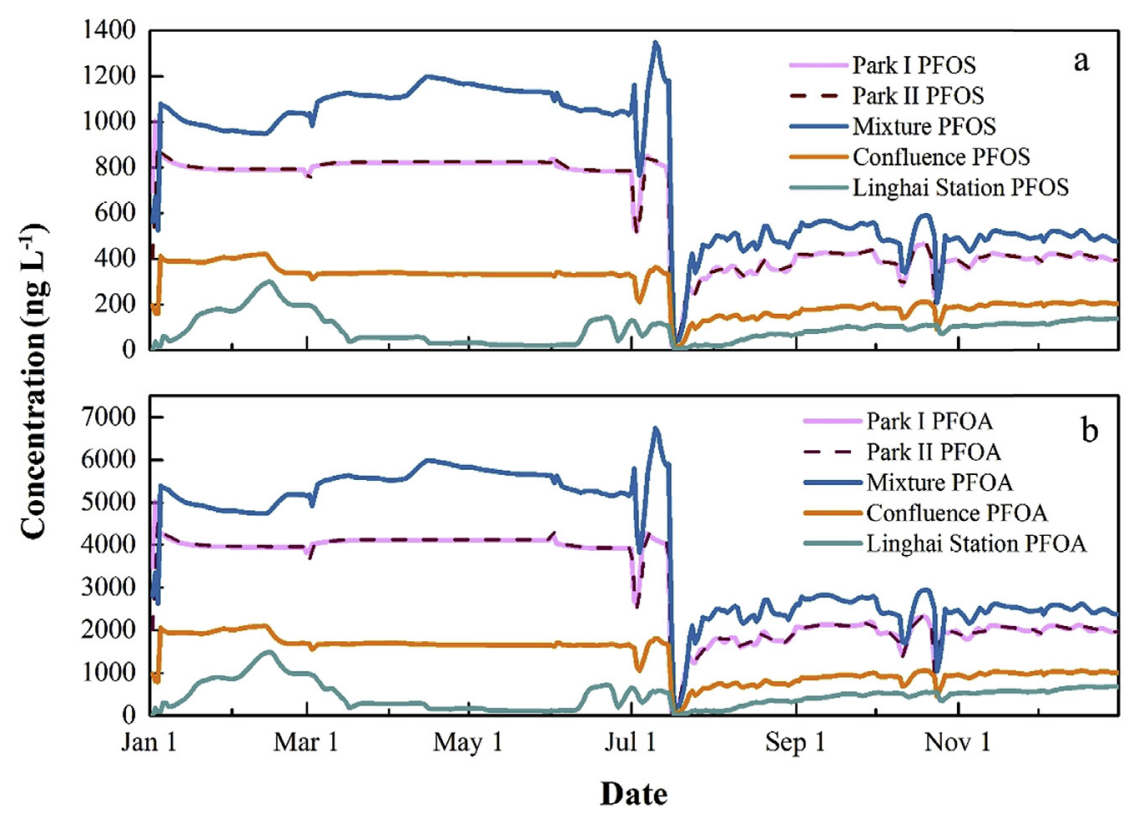

Fig. 5. The modeled PFOS (a) and PFOA (b) concentration at the fluorochemical park I and II, mixture area, confluence and Linghai Station.
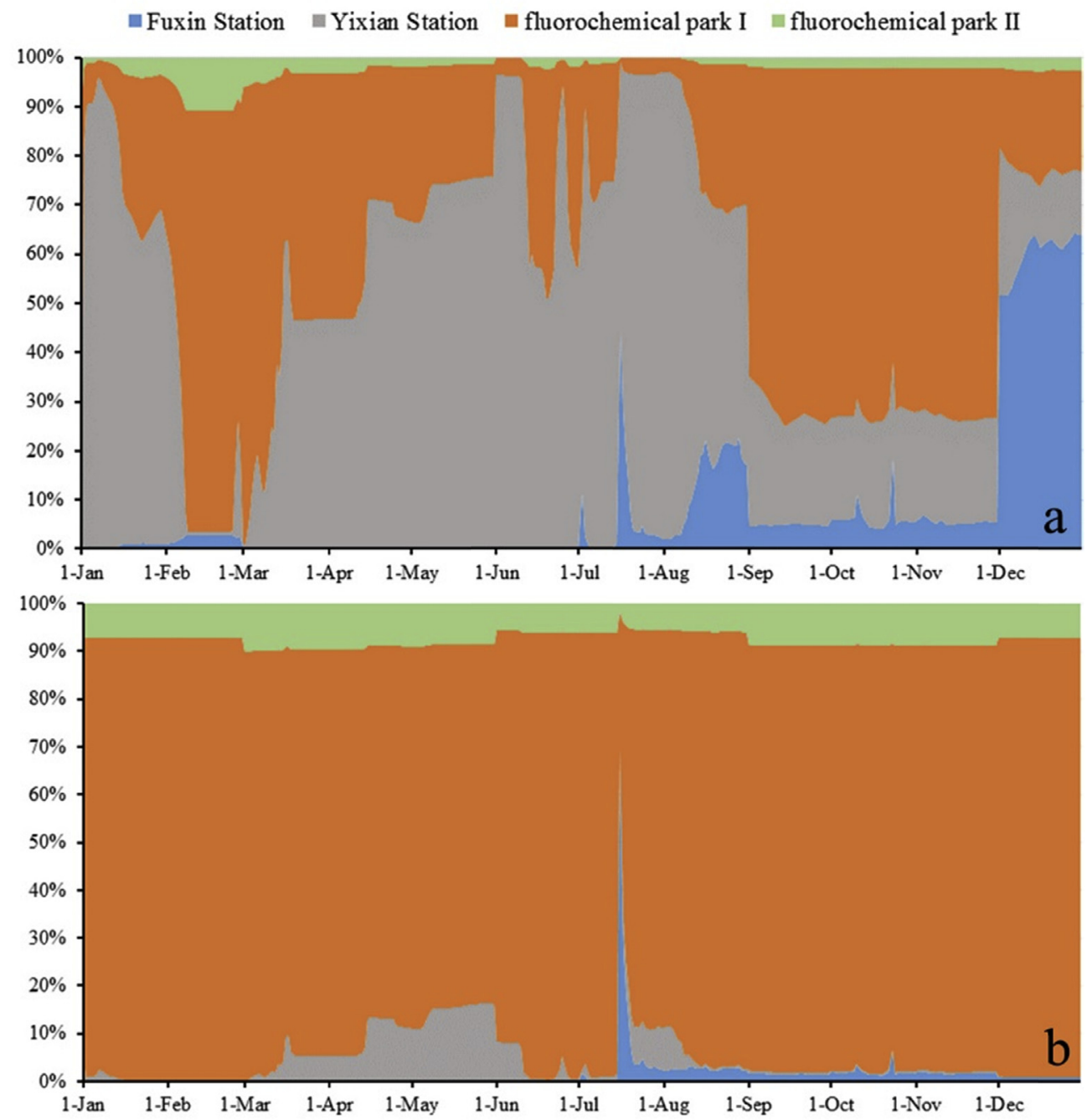

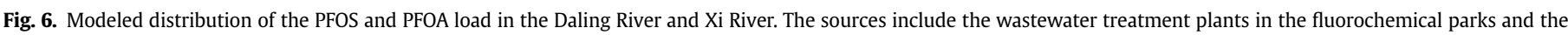
model boundaries at the Yixian Station and Fuxin Station. 
near the Liaodong Bay when the assumed load was released from the two fluorochemical parks. Comparatively, the total measure PFOS and PFOA loads of the fluorochemical park I are 2.46 and $26.33 \mathrm{~kg} \mathrm{y}^{-1}$, and the total measure PFOS and PFOA loads of the fluorochemical park II are 0.16 and $2.1 \mathrm{~kg} \mathrm{y}^{-1}$, respectively. The total load would probably reach a magnitude of $36.60 \mathrm{~kg} \mathrm{y}^{-1}$ for PFOS and $185.78 \mathrm{~kg} \mathrm{y}^{-1}$ for PFOA only if new fluorochemical industries were established in the watershed or the product capacity was in the maximum.

However, because there is no guideline established in China for PFOS and PFOA in the water quality and the emission from the industry at present, the question is whether the guideline value in this study is well fitted in this area. In the other hand, it must be noted that if PFOS or PFOA does not exceed a harmful level to the estuary and the river ecosystem, there is no guarantee it would not cause harmful effects together with other contaminants.

\subsection{The role of fluorochemical park as PFOS and PFOA sources to surface waters}

Fig. 6 represents the distribution of PFOS and PFOA load between the sources, including the fluorochemical park and the mass loads through the model boundaries in the Daling River and $\mathrm{Xi}$ River. The loads were simulated according to the modeling scenario 1. According to the simulation results all the fluorochemical parks contribute an average of $44.57 \%$ of the total PFOS and $95.44 \%$ of the total PFOA flow that reaches to the estuary. By far, the largest PFOS load came through the Yixian Station boundary (on average 47\%) from source other than the fluorochemical park, and the largest PFOA load came from the fluorochemical park I (on average 87.68\%). Only Fuxin Station (on average 8.36\%) and fluorochemical park II (on average $2.63 \%$ ) had a noticeable effect on the total PFOS load, while Fuxin Station (on average 1.17\%), Yixian Station (on average $3.39 \%$ ) and fluorochemical park II (on average 7.76\%) had a little effect on the total PFOA load. The effect of the fluorochemical parks was tremendous in PFOA load than PFOS load.

It was hypothesized that the water discharge and concentrations of PFOS and PFOA in water were stable and the emissions of industrial parks were continuous during the whole season (Xie et al., 2013). Based on this hypothesis, PFOS and PFOA mass flows were roughly estimated according to the modeling PFOS and PFOA concentrations with water discharge data. The PFOS mass flow at the Fuixn Station, Yixian Station, fluorochemical park I and II are $0.098 \mathrm{~kg} \mathrm{y}^{-1}, 4.64 \mathrm{~kg} \mathrm{y}^{-1}, 2.46 \mathrm{~kg} \mathrm{y}^{-1}$ and $0.16 \mathrm{~kg} \mathrm{y}^{-1}$, respectively. The PFOA mass flow at the Fuixn Station, Yixian Station, fluorochemical park I and II are $0.77 \mathrm{~kg} \mathrm{y}^{-1}, 1.05 \mathrm{~kg} \mathrm{y}^{-1}, 26.33 \mathrm{~kg} \mathrm{y}^{-1}$ and $2.1 \mathrm{~kg} \mathrm{y}^{-1}$, respectively. It is similar with our previous results (Zhu et al., 2015) but not for the fluorochemical park II. The reason is that we use the emission water data in this study while discharge data was used in the previous study.

In the estuary, the PFOS and PFOA mass flow, flowed into the Liaodong bay in Bohai Sea, was calculated. The PFOS mass flow is $1.74 \mathrm{~kg} \mathrm{y}^{-1}$, which is higher than the previous study $\left(0.91 \mathrm{~kg} \mathrm{y}^{-1}\right)$, and the PFOA mass flow is $40.57 \mathrm{~kg} \mathrm{y}^{-1}$, which is lower than the previous study (71.56 $\left.\mathrm{kg} \mathrm{y}^{-1}\right)$.

To sum up the modeling results, from scenario 1 , the mean absolute errors divided by the mean of measured concentrations were $41-64 \%$ for PFOS and $29-36 \%$ for PFOA. In scenario 2 , the result indicates that PFOS and PFOA in the Daling River at the downstream would not reach a harmful level with the current load. In scenario 3 , the fluorochemical parks contributed an average of $44.57 \%$ of the total PFOS and $95.44 \%$ of the total PFOA flow that reaches at the estuary. The mass flow was calculated as $1.74 \mathrm{~kg} \mathrm{y}^{-1}$ for PFOS and $40.57 \mathrm{~kg} \mathrm{y}^{-1}$ for PFOA to the Bohai Sea.

\section{Conclusions}

In the present study, the maximum concentrations of PFOS and PFOA were observed as $482.99 \mathrm{ng} \mathrm{L}^{-1}$ and $2279 \mathrm{ng} \mathrm{L}^{-1}$, respectively. The comparative study suggests that the PFAAs pollution of the study area is moderate on a global level and were found lower than the level of available level criteria of USEPA. However, the results presented in the present study indicate that the Daling River and its tributary seems to act as the major source of PFOS and PFOA emission into the Bohai Sea Region where they are mobilized in waterways via the Liaodong Bay into the Bohai Sea and cause wider environmental and human contamination. The PFOS and PFOA concentrations varied during transport. This is strongly connected with hydrological and meteorological conditions. This study simulation helps to determine the amount of concentration and how long the PFAAs will come in any section and any place away from the pollution point. The findings of the present study will assist in monitoring the status and trends of emerging POPs and will help the determination of the risk to both humans and wildlife, in the estuarine and coastal areas of the Bohai Sea, China. The methodology used in this study may serve as a model for assessment of other POP's production sites in the implementation of the Stockholm Convention recommendations.

\section{Acknowledgements}

This study was supported by the National Natural Science Foundation of China under Grant No. 41571478 and 41371488, the National Water Pollution Control and Treatment Science and Technology Major Project with Grant No. 2015ZX07203-005. We would like to thank the editors and reviewers for their valuable comments and suggestions.

\section{Appendix A. Supplementary data}

Supplementary data related to this article can be found at http:// dx.doi.org/10.1016/j.chemosphere.2016.09.119.

\section{References}

Annual hydrological report, P.R.China, 2013. Hydrological Data of Liaohe River Basin No.4 Basin of Raoyanghe River and Dalinghe River, Coastal Rivers of Liaoning, vol. 2.

DHI (Danish Hydraulic Institute), 2009. MIKE 11: a Modeling System for Rivers and Channels. Reference Manual. Danish Hydraulic Institute, Denmark.

Doulgeris, C., Georgiou, P., Papadimos, D., Papamichail, D., 2012. Ecosystem approach to water resources management using the MIKE 11 modeling system in the Strymonas River and Lake Kerkini. J. Environ. Manag. 94, 132-143.

Earnshaw, M.R., Paul, A.G., Loos, R., Tavazzi, S., Paracchini, B., Scheringer, M. Hungerbühler, K., Jones, K.C., Sweetman, A.J., 2014. Comparing measured and modelled PFOS concentrations in a UK freshwater catchment and estimating emission rates. Environ. Int. 70, 25-31.

Eisakhani, M., Abdullah, M.P., Karim, O.A., Malakahmad, A., 2012. Validation of MIKE 11 model simulated data for biochemical and chemical oxygen demands transport. Am. J. Appl. Sci. 9, 382.

FEPA, 2015. Fuxin Environmental Protection Administration retrieved from. http:// hbj.fuxin.gov.cn/ (accessed in December 2015).

Fu, J., Gao, Y., Wang, T., Liang, Y., Zhang, A., Wang, Y., Jiang, G., 2015. Elevated levels of perfluoroalkyl acids in family members of occupationally exposed workers: the importance of dust transfer. Sci. Rep. 5, 9313.

Gao, Y., Fu, J., Zeng, L., Li, A., Li, H., Zhu, N., Liu, R., Liu, A., Wang, Y., Jiang, G., 2014. Occurrence and fate of perfluoroalkyl substances in marine sediments from the Chinese Bohai Sea, Yellow Sea, and East China Sea. Environ. Pollut. 194, 60-68.

Giesy, J.P., Kannan, K., 2001. Global distribution of perfluorooctane sulfonate in wildlife. Environ. Sci. Technol. 35, 1339-1342.

Giesy, J.P., Kurunthachalam, K., 2002. Perfluorochemical surfactants in the environment. Environ. Sci. Technol. 36, 146A-152A.

Happonen, M., Koivusalo, H., Malve, O., Perkola, N., Juntunen, J., Huttula, T., 2016. Contamination risk of raw drinking water caused by PFOA sources along a river reach in south-western Finland. Sci. Total Environ. 541, 74-82.

Inspectorate, U.D.W, 2009. Guidance on the Water Supply (Water Quality) Regulations 20001 Specific to PFOS (Perfluorooctane Sulphonate) and PFOA 
(Perfluorooctanoic Acid) Concentrations in Drinking Water. Saatavissa. Viitattu 26.6. 2014. http://dwi.defra.gov.uk/stakeholders/informationletters/2009/10_ 2009annex. pdf.

Jiang, W., Zhang, Y., Yang, L., Chu, X., Zhu, L., 2015. Perfluoroalkyl acids (PFAAs) with isomer analysis in the commercial PFOS and PFOA products in China. Chemosphere $127,180-187$.

Johannessen, O.M., Volkov, V.A., Pettersson, L.H., Drange, H., Gao, Y., Maderich, V.S., Neelov, I.A., Nielsen, S.P., Bobylev, L.P., Stepanov, A.V., 2011. Radioactivity and Pollution in the Nordic Seas and Arctic: Observations, Modeling and Simulations. Springer Science \& Business Media.

Kaiglová, J., Jiřinec, P., Langhammer, J., Ingeduldová, E., Chalupová, D., Ferenčík, M., Jánský, B., 2015. Numerical modeling of heavily polluted fine-grained sediments remobilization in northern Czech Republic. Ecohydrol. Hydrobiol. 15, 111-124.

Lein, N.P.H., Fujii, S., Tanaka, S., Nozoe, M., Tanaka, H., 2008. Contamination of perfluorooctane sulfonate (PFOS) and perfluorooctanoate (PFOA) in surface water of the Yodo River basin (Japan). Desalination 226, 338-347.

Li, L., Zhai, Z., Liu, J., Hu, J., 2015. Estimating industrial and domestic environmental releases of perfluorooctanoic acid and its salts in China from 2004 to 2012. Chemosphere 129, 100-109.

Liu, S., Lu, Y., Xie, S., Wang, T., Jones, K.C., Sweetman, A.J., 2015. Exploring the fate, transport and risk of Perfluorooctane Sulfonate (PFOS) in a coastal region of China using a multimedia model. Environ. Int. 85, 15-26.

Liu, Z., Lu, Y., Wang, T., Wang, P. Li, Q., Johnson, A.C., Sarvajayakesavalu, S. Sweetman, A.J., 2016. Risk assessment and source identification of perfluoroalkyl acids in surface and ground water: spatial distribution around a mega-fluorochemical industrial park, China. Environ. Int. 91, 69-77.

Miyake, Y., Kobayashi, T., Kameya, T., Managaki, S., Amagai, T., Masunaga, S., 2014. Comparison study on observed and estimated concentrations of perfluorooctane sulfonate using a fate model in Tokyo Bay of Japan. J. Environ. Sci. Health Part A Toxic hazard. Subst. Environ. Eng. 49, 770-776.

Moshenberg, K.L., 2013. Fate and Transport Modeling of Cohesive Sediment and Sediment-bound HCB in the Middle Elbe River Basin.

Naile, J.E., Khim, J.S., Wang, T., Chen, C., Luo, W., Kwon, B.-O., Park, J., Koh, C.-H., Jones, P.D., Lu, Y., 2010. Perfluorinated compounds in water, sediment, soil and biota from estuarine and coastal areas of Korea. Environ. Pollut. 158, $1237-1244$.

Prevedouros, K., Cousins, I.T., Buck, R.C., Korzeniowski, S.H., 2006. Sources, fate and transport of perfluorocarboxylates. Environ. Sci. Technol. 40, 32-44.

Quinete, N., Wu, Q., Zhang, T., Yun, S.H., Moreira, I., Kannan, K., 2009. Specific profiles of perfluorinated compounds in surface and drinking waters and accumulation in mussels, fish, and dolphins from southeastern Brazil. Chemosphere 77, 863-869.

Rostkowski, P., Yamashita, N., So, I.M.K., Taniyasu, S., Lam, P.K.S., Falandysz, J., Lee, K.T., Kim, S.K., Khim, J.S., Im, S.H., 2006. Perfluorinated compounds in streams of the Shihwa industrial zone and Lake Shihwa, South Korea. Environ. Toxicol. Chem. 25, 2374-2380.
Sakurai, T., Serizawa, S., Isobe, T., Kobayashi, J., Kodama, K., Kume, G., Lee, J.-H. Maki, H., Imaizumi, Y., Suzuki, N., 2010. Spatial, phase, and temporal distributions of perfluorooctane sulfonate (PFOS) and perfluorooctanoate (PFOA) in Tokyo Bay, Japan. Environ. Sci. Technol. 44, 4110-4115.

Sharma, B.M., Bharat, G.K., Tayal, S., Larssen, T., Bečanová, J., Karásková, P., Whitehead, P.G., Futter, M.N., Dan, B., Nizzetto, L., 2015. Perfluoroalkyl substances (PFAS) in river and ground/drinking water of the Ganges River basin: emissions and implications for human exposure. Environ. Pollut. 208, 704-713.

Sun, Y Wang T, Peng X. Wang P, Lu, Y 2016. Bacterial community compositions in sediment polluted by perfluoroalkyl acids (PFAAs) using Illumina highthroughput sequencing. Environ. Sci. Pollut. Res. 23, 1-10.

Thanh, W., Yawei, W., Chunyang, L., Yaqi, C., Guibin, J., 2009. Perspectives on the inclusion of perfluorooctane sulfonate into the Stockholm convention on persistent organic pollutants. Environ. Sci. Technol. 43, 5171-5175.

USEPA, 2009. Provisional Health Advisories for Perfluorooctanoic Acid (PFOA) and Perfluorooctane Sulfonate (PFOS).

Wang, P., Lu, Y., Wang, T., Meng, J., Li, Q., Zhu, Z., Sun, Y., Wang, R., Giesy, J.P., 2016. Shifts in production of perfluoroalkyl acids affect emissions and concentrations in the environment of the Xiaoqing River Basin, China. J. Hazard. Mater. 307, $55-63$.

Wang, P., Wang, T., Giesy, J.P., Lu, Y., 2013. Perfluorinated compounds in soils from Liaodong Bay with concentrated fluorine industry parks in China. Chemosphere 91, 751-757.

Wang, T., Pei, W., Jing, M., Liu, S., Lu, Y., Khim, J.S., Giesy, J.P., 2014. A review of sources, multimedia distribution and health risks of perfluoroalkyl acids (PFAAs) in China. Chemosphere 129, 87-99.

Wang, T., Wang, P., Meng, J., Liu, S., Lu, Y., Khim, J.S., Giesy, J.P., 2015a. A review of sources, multimedia distribution and health risks of perfluoroalkyl acids (PFAAs) in China. Chemosphere 129, 87-99.

Wang, Z., Cousins, I.T., Scheringer, M., Hungerbuehler, K., 2015b. Hazard assessment of fluorinated alternatives to long-chain perfluoroalkyl acids (PFAAs) and their precursors: status quo, ongoing challenges and possible solutions. Environ. Int. $75,172-179$

Xie, S., Wang, T., Liu, S., Jones, K.C., Sweetman, A.J., Lu, Y., 2013. Industrial source identification and emission estimation of perfluorooctane sulfonate in China. Environ. Int. 52, 1-8.

Yamashita, N., Kannan, K., Taniyasu, S., Horii, Y. Petrick, G. Gamo, T. 2005. A globalsurvey of perfluorinated acids in oceans. Mar. Pollut. Bull. 51, 658-668.

Zhao, X., Li, J., Shi, Y., Cai, Y., Mou, S., Jiang, G., 2007. Determination of perfluorinated compounds in wastewater and river water samples by mixed hemimicellebased solid-phase extraction before liquid chromatography-electrospray tandem mass spectrometry detection. J. Chromatogr. A 1154, 52-59.

Zhu, Z., Wang, T., Meng, J., Wang, P., Li, Q., Lu, Y., 2015. Perfluoroalkyl substances in the Daling River with concentrated fluorine industries in China: seasonal variation, mass flow, and risk assessment. Environ. Sci. Pollut. Res. 22, 10009-10018. 